\title{
SIMILARIDADE GENÉTICA DE CULTIVARES DE MANDIOCA (Manihot esculenta) POR MEIO DE MARCADORES RAPD
}

\begin{abstract}
RESUMO - O objetivo deste trabalho foi analisar a divergência genética entre 27 acessos de mandioca provenientes do banco ativo de germoplasma da Embrapa Amazônia Oriental. Foram utilizados 12 primers, onde todos apresentaram polimorfismo. Foram analisadas 73 bandas polimórficas de um total de 211 bandas amplificadas. A análise de divergência genética foi realizada a partir do programa NTSYS-pc, 2.02, utilizando o coeficiente de Jaccard. Na análise do dendograma, foram observados dois grupos principais. No primeiro grupo, que se subdividiu em dois subgrupos, com coeficiente de
\end{abstract}

\author{
MARIA ROSA COSTA ${ }^{1}$ \\ ELOISA RAMOS CARDOSO
MUTSUMI MINATO OHAZE \\ ELOISA RAMOS CARDOSO
MIRIÃ MUTSUMI MINATO OHAZE
}

similaridade, variando de $8 \%$ a $78 \%$, incluem-se 20 materiais, oriundos de diferentes localidades. O segundo grupo dividiu-se em dois subgrupos, com similaridade genética, variando de $9 \%$ a $38 \%$. Os acessos CPATU 260 e CPATU 137 foram distintos, em relação ao restante, constituindo subgrupos isolados, dentro do seu grupo. Os resultados obtidos mostraram variabilidade genética potencial para o programa de melhoramento genético e informações úteis, para o direcionamento de coleta de germoplasma de mandioca para enriquecimento do BAG.

TERMOS PARA INDEXAÇÃO: Marcadores moleculares, RAPD, mandioca, biologia molecular, Manihot esculenta.

\section{GENETIC CHARACTERIZATION OF CASSAVA (Manihot esculenta) BY RAPD MARKERS}

\begin{abstract}
The aim of this work was to analyse the genetic diversity among twenty seven access of cassava (Manihot esculenta) from Embrapa Eastern Amazon Germoplasm Collection. All twelve RAPD primers utilized to amplify the DNA showed polimorfism in Manihot esculenta. From a total of two hundred and eleven bands, it was selected seventy three polimorphic bands. Genetic divergence analysis was carried out by NTSYS-pc, 2.02 and Jaccard coefficient. The dendogram analysis showed two different groups. The
\end{abstract}

INDEX THERMS: Favor colocar

\section{INTRODUÇÃO}

A mandioca (Manihot esculenta Crantz) é uma importante fonte de calorias que estão armazenadas na raiz, sob a forma de fécula, constituindo a base alimentar de grande parte da população (cerca de 500 milhões de pessoas) da África, Ásia e América Latina. Com uma produção de 3.500.000 t de raízes, o Pará destaca-se first group, which was splited in two small groups (genetic similarity varied from $8 \%$ to $78 \%$ ), included twenty access originated of different locals. The second group was split in two small groups (genetic similarity varied from $9 \%$ to $38 \%$ ). The access CPATU 260 and CPATU 137 were shown to be the most divergent and to belong to distinct groups. In conclusion, the results showed genetic diversity that can be used in breeding programs and in strategies to manage germoplasm collection of cassava.

como o maior produtor nacional de mandioca e responde por $70 \%$ da produção na Região Norte. Nesse Estado, há grande diversificação do uso da mandioca, que vai da alimentação animal à humana, sob as formas "in natura" e de produtos processados, agregando maior valor ao produto final.

1. Engenheiro Agrônomo, M.Sc. Genética e Melhoramento de Plantas, Embrapa Amazônia Oriental. Caixa Postal 48, 66017-970 - Belém, PA.

2. Engenheiro Agrônomo, M.Sc. Fitotecnia, Embrapa Amazônia Oriental.

3. Bolsista PIBIC/CNPq/Embrapa. 
Além da reconhecida importância social e econômica como cultura alimentar e de aplicação industrial, o Brasil é considerado o principal centro de diversidade (Rogers \& Appan, 1973) e a Amazônia, o provável centro de origem da espécie (Allem, 1994). A caracterização e avaliação do germoplasma, quanto ao seu potencial de uso, segundo (Morales1995), representa um componente estratégico para as atividades de pesquisa e desenvolvimento, agregando valor ainda maior, se estiver adicionado o conhecimento etnobiológico e definidas sequiências moleculares de interesse social e industrial. Dentre os marcadores o RFLP e RAPD podem ser utilizados para determinar, a baixo custo, padrões de diversidade, nas coleções de germoplasma (Dodds \& Watanabe, 1990).

A biodiversidade representa um importante bem socioeconômico e, dentro deste contexto, a Amazônia se configura como um grande depositário de recursos genéticos de mandioca. Os acessos coletados na Amazônia possuem alto valor, pela qualidade e adaptação às condições ecológicas locais. Com o avanço alcançado em recentes estudos, desenvolvidos por Carvalho et al. (2000), na área de biologia molecular e bioquímica, aumentam as perspectivas de que, num futuro próximo, essa planta venha atender às demandas por alimentos alternativos e fármacos produzidos pela bioindústria, integrando a mandioca aos demais setores da economia.

Os acessos de mandioca do Brasil estão distribuídos em sete bancos ativos de germoplasma regionais, localizados na Amazônia (Oriental e Ocidental), Tabuleiros Costeiros, Semi-árido, Cerrados, Subtrópico e em Campinas-SP. Apesar da reconhecida variabilidade genética existente nesses bancos, o germoplasma de mandioca tem sido pouco estudado, sob o ponto de vista genético. É importante conhecer a maneira como essa variabilidade está distribuída. É essencial conhecer a estrutura genética, uma vez que, os padrões de distribuição da variabilidade genética estão correlacionados com o sistema reprodutivo. A escassez de informações, principalmente aquelas relacionadas à documentação e caracterização genética, culminando com a carência de estudos sobre o conhecimento da diversidade genética das espécies, com potencial econômico para a região, faz com que a conservação e caracterização de germoplasma se torne necessária visando assegurar informações sobre essas fontes de genes para a utilização futura que, além de prevenir a perda desses recursos são fundamentais para o sucesso da produção agrícola. Os marcadores de DNA representam ferramentas importantes em estudos de evolução, domesticação, ecologia, filogenia, mapeamento genético e clonagem de genes. Estes marca- dores permitem a avaliação, em curto prazo, de um número elevado de genótipos, além de não sofrerem influência ambiental, como ocorre com marcadores morfológicos. Em estudos de diversidade genética em mandioca, marcadores bioquímicos (isoenzimas) e moleculares (RAPD, Microssatélites, AFLP, etc.) tem sido empregados com sucesso, como os desenvolvidos por Elias et al. (1998), Carvalho et al. (1998, 2000), Colombo (1997), Faraldo (1999), Sambatti (1998), Peroni (1998) e Mühlen (1999). O uso combinado de marcadores morfológicos e moleculares subsidiará os trabalhos de melhoramento, na busca de cultivares mais produtivos e com características de qualidade que atendam as demandas do setor produtivo, contribuindo, ainda, para o intercâmbio de material e de informações entre instituições de pesquisa. Neste sentido, foi instalado o Banco de germoplasma de mandioca da Embrapa Amazônia Oriental, localizado em Belém-PA. Os acessos foram coletados em pequenas comunidades consideradas "reservatórios genéticos," que devem ser mantidos e preservados. O objetivo deste estudo foi examinar o polimorfismo gerado por marcadores RAPD e analisar a diversidade genética, entre acessos de mandioca, de diferentes procedências, pertencentes ao Banco Ativo de Germoplasma (BAG) da Embrapa Amazônia Oriental.

\section{MATERIAL E MÉTODOS}

\section{Material vegetal e extração de DNA}

O material investigado foi composto de 27 acessos de mandioca (Tabela 1), provenientes do Banco Ativo de Germoplasma da Embrapa Amazônia Oriental, em Belém, PA. O DNA genômico foi obtido através de folhas, em estádio médio de desenvolvimento, recémcoletadas que, após desinfecção, foram maceradas com nitrogênio líquido e cerca de $200 \mathrm{mg}$ de pó foram transferidos para tubos eppendorf. Adicionou-se, em seguida, $700 \mu \mathrm{l}$ de solução extratora contendo CTAB $20 \%$, Na$\mathrm{Cl}$ 5M, Tris-HCl 1M, EDTA 0,5M e PVP. Os tubos foram agitados e colocados em banho-maria a $60^{\circ} \mathrm{C}$, durante 60 minutos. $\mathrm{O}$ extrato foi misturado com $700 \mu \mathrm{l}$ de clorofórmio-álcool isoamil (24:1), para formar uma emulsão. Após centrifugar por 10 minutos a $4{ }^{0} \mathrm{C}$ e $12.000 \mathrm{rpm}$, a parte superior aquosa foi cuidadosamente isolada e submetida a álcool $95 \%$, o que ocasionou a precipitação do DNA. O material foi colocado em freezer $\left(-20^{\circ} \mathrm{C}\right)$ por 20 minutos, sendo, em seguida, centrifugado por 10 minutos a $4{ }^{0} \mathrm{C}$ e $12.000 \mathrm{rpm}$, lavado com etanol $70 \%$, para remover sais e, posteriormente, seco à temperatura ambiente, por aproximadamente 12 horas. O DNA foi ressuspendido com $100 \mu$ RNAse/ TE 
(10ug.ml $\mathrm{l}^{-1}$ ). A concentração de DNA foi estimada em gel de agarose $1,0 \%$, pela comparação do DNA total com três concentrações do DNA lambda. As amostras utilizadas no RAPD, após a quantificação total, partiram de diluições da amostra total em água estéril, de modo a conter $5 \mathrm{ng} / \mu \mathrm{l}$ de DNA. As alíquotas foram armazenadas a $-20^{\circ} \mathrm{C}$.

TABELA 1 - Identificação das cultivares analisadas. Belém, Pará. 2001.

\begin{tabular}{|c|c|c|}
\hline N\%/código & Origem/localidade & Cultivar/variedade \\
\hline M1/cpatu 263 & Medicilândia/PA/Brasil & Pingo de Ouro \\
\hline M2/ cpatu 135 & Santarém/PA/Brasil & Ouricuri \\
\hline M3/ cpatu 215 & Belterra/PA/Brasil & Belterra \\
\hline M4/ cpatu 137 & Lábrea/AMBrasil & Jamamadi-1 \\
\hline M5/ cpatu 043 & Pernambuco/Brasil & Imitação \\
\hline M6/ cpatu0 61 & Bragança/PA/Brasil & Maranhense-1 \\
\hline M7/ cpatu0 58 & Araguaia/PA/Brasil & Amarela-2 \\
\hline M8/ cpatu 061 & PA/Brasil & Jararaca-1 \\
\hline M9/ cpatu 197 & Acre/Brasil & Carauaçu-2 \\
\hline M10/ cpatu 217 & Araguaia/PA/Brasil & Amarela \\
\hline M11/ cpatu 264 & Cururupu/MA/Brasil & Pingo de Ouro \\
\hline M12/ cpatu 036 & Bragança/PA/Brasil & Maranhense-2 \\
\hline M13/ cpatu 035 & Capanema/PA/Brasil & Iracema-1 \\
\hline M14/ cpatu 260 & PA/Brasil & Macaxeira Olho Preto \\
\hline M15/ cpatu 204 & Alenquer/PA/Brasil & Olho Verde-2 \\
\hline M16/ cpatu 288 & CNPMF/BA/Brasil & Iracema-02-0020 \\
\hline M17/ cpatu 167 & CNPMF/BA/Brasil & Engana Ladrão \\
\hline M18/ cpatu 022 & Bragança/PA/Brasil & Xingu \\
\hline M19/ cpatu 022 & Bragança/PA/Brasil & BGM 019 \\
\hline M20/ cpatu 320 & Bragança/PA/Brasil & Macaxeira Branquinha-02 \\
\hline M21/ cpatu 319 & IPEANE/PE/Brasil & Engana Ladrão-0080 \\
\hline M22/ cpatu173 & Manaus/Brasil & IM 186 \\
\hline M23/ cpatu 299 & CPATU/Brasil & IM186-1 \\
\hline M24/ cpatu 165 & Manacapuru/AM/Brasil & Macaxeira Pão Manaus \\
\hline M25/ cpatu 021 & Bragança/PA/Brasil & Olho Verde-01 \\
\hline M26/ cpatu 271 & Tabatinga/AM/Brasil & Macaxeira Açaí \\
\hline M27/ cpatu 261 & Vizeu/PA/Brasil & Macaxeira Vizeu \\
\hline
\end{tabular}

Ciênc. agrotec., Lavras. V.27, n.1, p.158-164, jan./fev., 2003 


\section{Análise RAPD}

Os primers utilizados foram: OPF04, OPF15, OPN07, OPN20, OPO05, OPO11, OPO12, OPS03, OPS05, OPT04, OPT06 e OPT07.

As reações foram desenvolvidas, de acordo com o protocolo de Williams et al. (1990), com pequenas modificações, num volume final de $13 \mu \mathrm{l}$, contendo água destilada autoclavada, $20 \mathrm{mM}$ Tris- $\mathrm{HCl}(\mathrm{pH} 8,0)$, $50 \mathrm{mM} \mathrm{KCl}, 2,0 \mathrm{mM} \mathrm{MgCl} 2,200 \mu \mathrm{M}$ de cada dNTP, BSA purificada $(2,5 \mathrm{mg} / \mathrm{ml}), 1,3 \mathrm{uM}$ primer arbitrário, 1U.I Taq DNA polimerase, $15 \mathrm{ng}$ de DNA genômico e por fim adicionadas duas gotas de óleo mineral.

As amplificações foram realizadas em termociclador de DNA Thermolyne Amplitron II modelo DB.80225, sendo realizados 40 ciclos de $1^{\prime}$ a $94^{\circ} \mathrm{C}, 1^{\prime}$ a $37^{\circ} \mathrm{C}$ e $2^{\prime}$ a $72^{\circ} \mathrm{C}$, seguidos de mais 7 minutos a $72^{\circ} \mathrm{C}$, para a completa extensão dos produtos amplificados. O método utilizado para a separação dos produtos amplificados foi à eletroforese horizontal, em gel de agarose $1,5 \%$, corado com brometo de etídio $1 \mathrm{mg} / \mathrm{ml}$. Utilizouse $13 \mu \mathrm{l}$ de cada reação, acrescido de $2 \mu \mathrm{l}$ de uma solução de azul de bromofenol (40 \%), mais sacarose. Foi utilizado TBE (Trizma base $0,1 \mathrm{M}$; ácido bórico $1 \mathrm{M}$ e EDTA 0,5M), como tampão do gel e de corrida.

Após a eletroforese, os géis foram visualizados e fotografados em equipamento de foto documentação. $\mathrm{O}$ padrão de peso molecular utilizado foi o $1 \mathrm{~Kb}$ ladder.

\section{Análise dos dados}

Inicialmente, foi construída uma matriz para os fragmentos polimórficos amplificados com presença (1) e ausência de banda (0). Somente foram consideradas as bandas que não davam margens a dúvidas. Bandas muito fracas, de difícil resolução, não foram incluídas. Para análise dos dados, utilizou-se o NTSYS-pc (Numerical Taxonomy and Multivariate Analysis System), versão 2.02. A similaridade entre as amostras foi estimada pelo coeficiente de Jaccard, que gerou a matriz de similaridade. A partir dessa matriz, foi gerado o cluster, pelo método UPGMA ("Unweighted Pair-Group Method Using Arithmetic Average").

\section{RESULTADOS E DISCUSSÃO}

Um total de 211 marcadores RAPD, com tamanhos variando de $300 \mathrm{a} 2200 \mathrm{pb}$, foram amplificados pelos 12 primers utilizados, dos quais 73 eram polimórficos, gerando $34,60 \%$ de polimorfismo. $\mathrm{O}$ número de marcadores amplificados variou de 24 (OPF-04) a 5 (OPN20). O número de fragmentos polimórficos por primer variou de 11 (OPS-03) a 1 (OPF-15 e OPN- 20). Observou-se, dentre os fragmentos amplificados, a ocorrência de bandas específicas aos indivíduos. Na Fig.1, podem ser visualizados exemplos destes marcadores. Foram estimados os índices de similaridade para todos os indivíduos analisados (tabela1). As maiores distâncias foram obtidas, comparando-se o CPATU 137, proveniente do Amazonas, com o CPATU 261 (3\%), proveniente do Pará. $\mathrm{O}$ segundo maior distanciamento genético foi entre os acessos CPATU 137, do Amazonas e o CPATU 35, do Pará $(8 \%)$ e os acessos CPATU 43, de Pernambuco, e CPATU 021, do Pará. Isto indica que estes acessos são candidatos potenciais como fonte de variabilidade, no programa de hibridização desta espécie, visando o melhoramento genético.

Na Figura 2, encontra-se o dendograma, gerado pelo método UPGMA, através do programa NTSYS-pc, 2.02. Esta análise de distância genética gerou o "cluster", que mostra a separação dos acessos, em dois grupos principais. No primeiro grupo, que se subdividiu em dois subgrupos, com coeficiente de similaridade, variando de $3 \%$ a $78 \%$, incluem-se 20 materiais, oriundos de diferentes localidades. No segundo grupo, que se dividiu em dois subgrupos, com similaridade genética, variando de $9 \%$ a $38 \%$, incluem-se quatro materiais de diferentes localidades. Os acessos CPATU 260 e CPATU 137 foram distintos, em relação ao restante, constituindo subgrupos isolados, dentro do seu grupo. Observou-se que o acesso CPATU 22 está duplicado no Banco.

Constatou-se neste trabalho, que não foi possível estruturar os genótipos, em função da origem geográfica, já que alguns genótipos da mesma localidade apresentaram distanciamento genético considerável, como é o caso dos acessos CPATU 61 e o CPATU 36, provenientes de Bragança, PA, cuja diversidade foi de $17 \%$. Os acessos CPATU 173 e CPATU 165 de Manaus, AM apresentaram diversidade de $16 \%$. Acredita-se que, por existirem nos bancos de germoplasma materiais oriundos de roças, lavouras comerciais e de programas de melhoramento com elevada frequiência de locos em heterose, exista grande variabilidade nos mesmos. Colombo et al. (2000), examinando o polimorfismo gerado por marcadores RAPD, em 126 genótipos de mandioca, concluíram haver uma fraca estruturação genética na mandioca, o que pode ocasionar sobreposição de genótipos de diferentes localidades. De acordo com estes autores, este fato é devido a fatores, como as trocas de material botânico, entre pequenos produtores, e a 


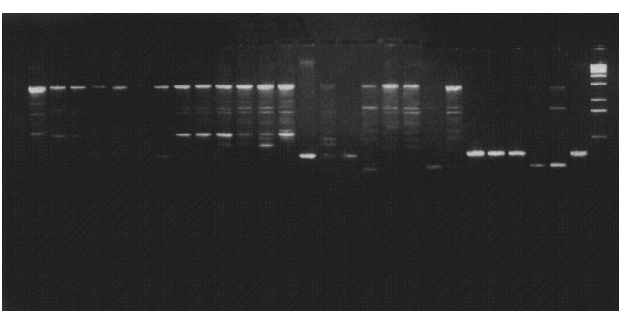

(A)

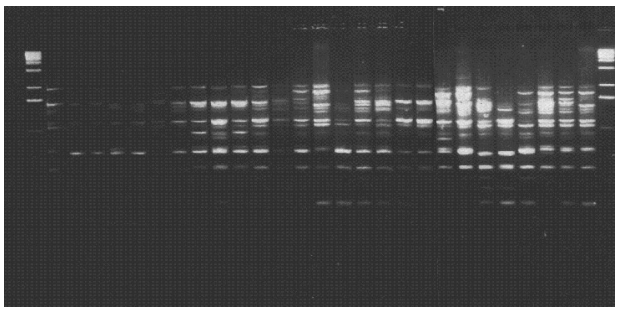

(B)

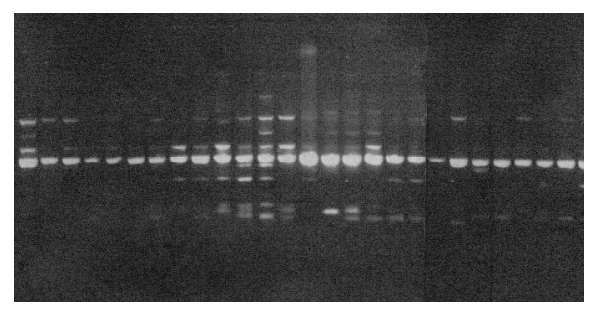

(C)

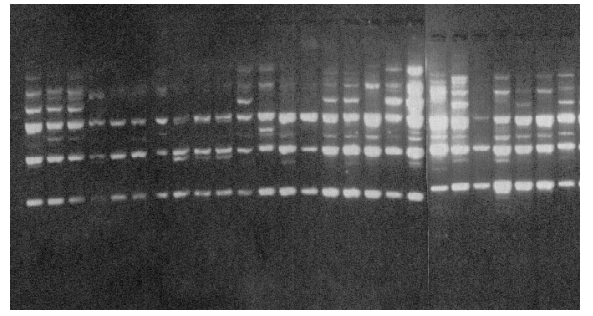

(D)

FIGURA 1 - Padrão de amplificação dos primers OPS 05 (A), OPS 03 (B), OPO 12 (C) e OPO 05 (D).

TABELA1 - Matriz de distância genética estimada pelo coeficiente de Jaccard para todos os indivíduos estudados, Belém,Pará, 2001.

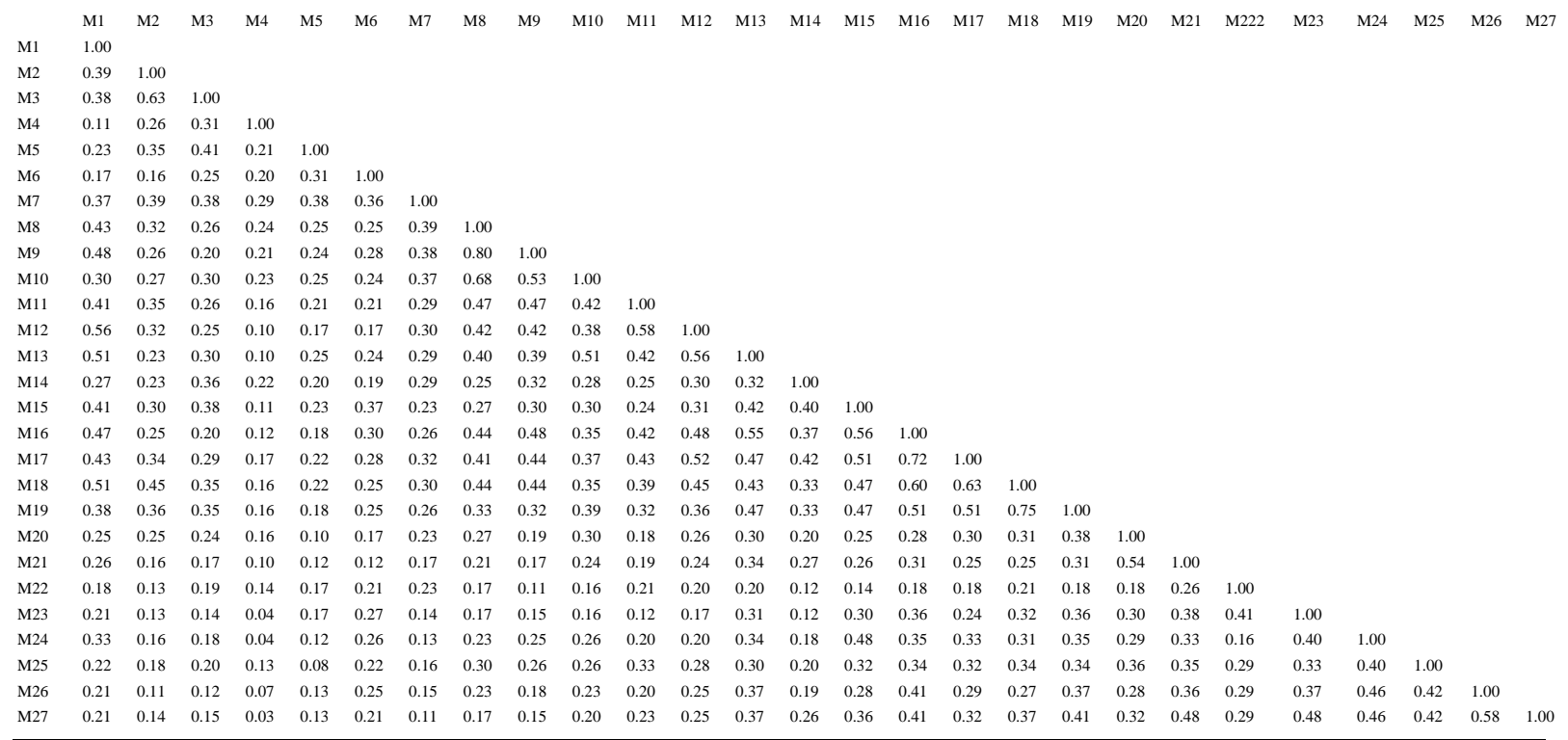

Ciênc. agrotec., Lavras. V.27, n.1, p.158-164, jan./fev., 2003 


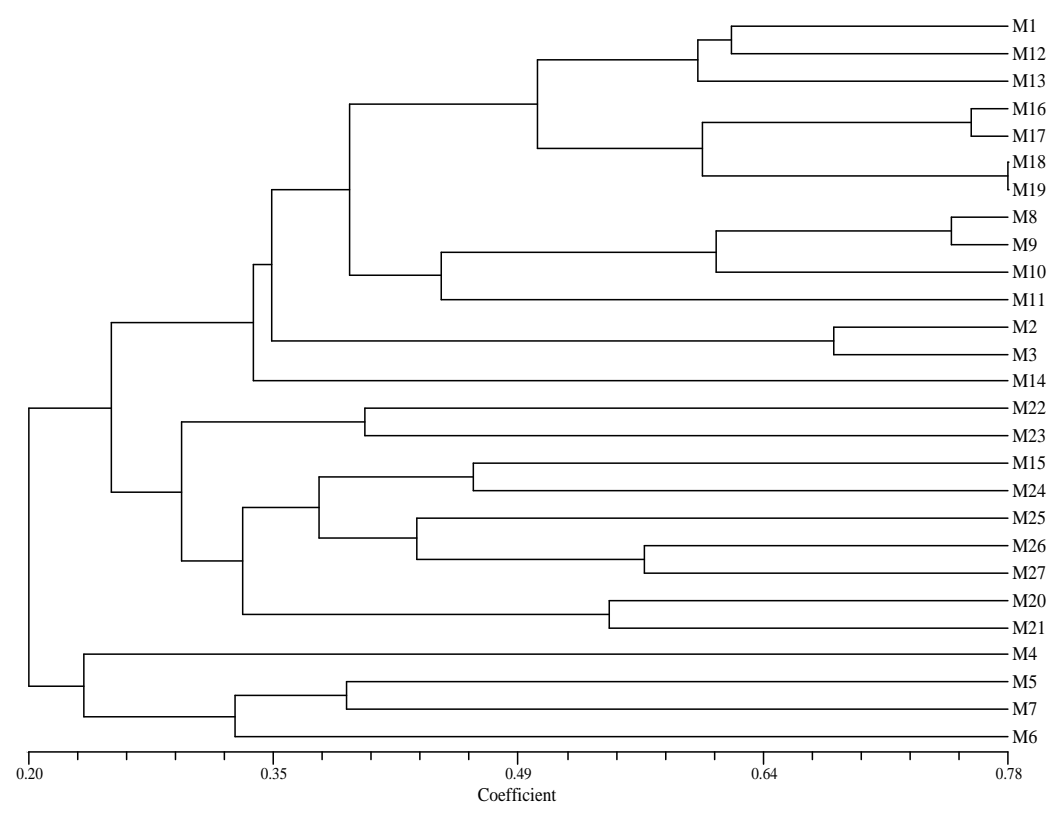

FIGURA 2 - Dendograma obtido pelo UPGMA para o coeficiente de Jaccard, para as 75 bandas polimórficas geradas pelo RAPD.

recombinação que pode ocorrer, entre genótipos plantados em uma mesma parcela, prática comum entre os produtores desta cultura. Mühlen (1999) analisando a divergência entre 55 materiais de mandioca, sendo 45 da Amazônia, nove de São Paulo e a cultivar Mantiqueira, com marcadores RAPD, observou que a variabilidade foi maior dentro dos grupos que entre os mesmos. Cabral (2001), analisando a variabilidade em 200 acessos de mandioca, através de isoenzimas, observou que ao agrupar os acessos pela origem, a variabilidade foi maior dentro dos grupos que entre os mesmos. A avaliação da diversidade genética utilizando marcadores moleculares tem confirmando a existência de grande variabilidade genética da mandioca. Alguns estudos comparativos entre espécies selvagens do gênero Manihot e a espécie cultivada $M$. esculenta têm indicado que as espécies selvagens contêm igual ou maior variabilidade genética que a mandioca cultivada (Mühlen, 1999). Peroni (1998) relatou que a diversidade genética encontrada dentro dos sistemas agrícolas tradicionais é semelhante a do centro de origem da espécie.

\section{CONCLUSÕES}

Os marcadores RAPD mostraram-se eficientes para detectar polimorfismo nesta espécie e podem ser utilizados como uma poderosa ferramenta, na obtenção de informações úteis para o manejo de coleções de germoplama e o direcionamento de programas de melhoramento genético.

Observou-se grande divergência em alguns materiais, oriundos da mesma localidade concluindose haver pouca relação entre a origem geográfica e o padrão da distribuição da variabilidade genética obtida.

\section{REFERÊNCIAS BILIOGRÁFICAS}

ALLEM, A. C. The origin of Manihot esculenta crantz (Euphorbiaceae). Genetic Resources and Crop evolution, Dordrecht, v. 41, p. 133-150, 1994.

CABRAL, B. L. R. Variabilidade isoenzimática de 200 acessos de mandioca (Manihot esculenta Crantz). 2001. 78 p. Dissertação (Mestrado) - Escola Superior de Agricultura Luiz Queiroz, Piracicaba.

CARVALHO, L. J. C. B.; CABRAL, G. B.; CAMPOS, L. Raiz de reserva de mandioca: um sistema biológico de múltipla utilidade. Brasília: Embrapa, 2000. 16 p. (Embrapa Recursos Genéticos e Biotecnologia. Documentos, 44). 
CARVALHO, L. J. C. B.; SCHAAL, B. A.; FUKUDA, W. M. G. Cassava (Manihot esculenta Crantz) phenetic relationships and genetic diversity revealed by morphological descriptors and RAPD markers. Revista Brasileira de Genética, Ribeirão Preto, v. 17, p. 13, 1998. Suplemento.

COLOMBO, C.; SECOND, G.; CHARRIER A. Diversity within American cassava germplasm based on RAPD markers. Genetics and Molecular Biology, Ribeirão Preto, v. 23, p. 189-199, 2000.

COLOMBO, C. A. Étude de la diversité génétique de maniocs américains (Manihot esculenta Crantz) par les marqueurs moléculaires (RAPD et AFLP). 1997. 145 p. Thèse (Doctorat) - École Nationale Superieure Agronomique de Montpellier, Montpellier.

DODS, J. H.; WATANABE, K. Biotechnological tools for plant genetic resources management. Diversity, Bethesda, v. 6, n. 3/4, p. 26-28, 1990.

ELIAS, M.; PANAUD, O.; MCKE, D. B.; ROBERT, T. Traditional cultivation of cassava among amerindians: consequences on genetic diversity assessed with AFLP markers. Revista Brasileira de Genética, Ribeirão Preto, v. 17, p. 16, 1998. Suplemento.

FARALDO, M. I. F. F. Distribuição da variabilidade genética e caracterização isoenzimática de etnovariedades em roças de mandioca (Manihot esculenta Crantz) do Brasil. 1999. 117 p. Tese (Doutorado) - Escola Superior de Agricultura Luiz Queiroz, Piracicaba.
MORALES, E. A. V. Recursos genéticos vegetais da Amazônia. Belém: [s.n.], 1995. 29 p. Apostila.

MÜHLEN, G. S. Avaliação da diversidade genética de etnovariedades de mandioca (Manihot esculenta Crantz) com marcadores de DNA: RAPD, AFLP e Microssatélites. 1999. 176 p. Tese (Doutorado) - Escola Superior de Agricultura Luiz Queiroz, Piracicaba.

PERONI, N. Taxonomia folk e diversidade intraespecífica de mandioca (Manihot esculenta Crantz) em roças de agricultura tradicional em áreas de Mata Atlântica do sul do Estado de São Paulo. 1998. 191 p. Dissertação (Mestrado) - Escola Superior de Agricultura Luiz Queiroz, Piracicaba.

ROGERS, D. J.; APPAN, S. G. Manihot and manihotoides (Euforbiaceae): a computer-assisted study. Flora Neotropica. New York: Hafner, 1973. 272 p. (Monograph, 13)

SAMBATTI, J. B. M. Erosão genética e conservação de germoplasma de mandioca na agricultura autóctone em Ubatuba-SP. 1998. 165 p. Dissertação (Mestrado) - Escola Superior de Agricultura Luiz Queiroz, Piracicaba.

WILLIAMS, J. G. K.; KUBELIK, A. R.; LIVAK, K. J.; RAFALSKI, J. A.; TINGEY, S. V. DNA polymorphisms amplified by arbitrary primers are useful as genetic markers. Nucleic Acids Research, Oxford, v. 18, p. 6531-6535, 1990 